\title{
Maintenance cognitive stimulation therapy for dementia: single-blind, multicentre, pragmatic randomised controlled trial
}

\author{
Martin Orrell, Elisa Aguirre, Aimee Spector, Zoe Hoare, Robert T. Woods, Amy Streater, \\ Helen Donovan, Juanita Hoe, Martin Knapp, Christopher Whitaker and lan Russell
}

\section{Background}

There is good evidence for the benefits of short-term cognitive stimulation therapy for dementia but little is known about possible long-term effects.

\section{Aims}

To evaluate the effectiveness of maintenance cognitive stimulation therapy (CST) for people with dementia in a single-blind, pragmatic randomised controlled trial including a substudy with participants taking acetylcholinesterase inhibitors (AChEIS).

\section{Method}

The participants were 236 people with dementia from 9 care homes and 9 community services. Prior to randomisation all participants received the 7-week, 14-session CST programme. The intervention group received the weekly maintenance CST group programme for 24 weeks. The control group received usual care. Primary outcomes were cognition and quality of life (clinical trial registration: ISRCTN26286067).

\section{Results}

For the intervention group at the 6-month primary end-point there were significant benefits for self-rated quality of life (Quality of Life in Alzheimer's Disease (QoL-AD) $P=0.03$ ). At 3 months there were improvements for proxy-rated quality of life (QoL-AD $P=0.01$, Dementia Quality of Life scale (DEMQOL) $P=0.03$ ) and activities of daily living $(P=0.04)$. The intervention subgroup taking AChEls showed cognitive benefits (on the Mini-Mental State Examination) at $3(P=0.03$ ) and 6 months $(P=0.03)$

\section{Conclusions}

Continuing CST improves quality of life; and improves cognition for those taking AChEls.

\section{Declaration of interest}

Royalties from the sale of the Making a Difference manuals are paid to the Dementia Services Development Centre, Bangor University.
There is good evidence for the benefits of cognitive stimulation for people with dementia. ${ }^{1}$ A recent Cochrane review showed that cognitive stimulation improved both cognition and quality of life. ${ }^{2}$ The review concluded that the benefits of cognitive stimulation enhanced those of medication, and that it was effective whether or not acetylcholinesterase inhibitors (AChEIs) were prescribed. ${ }^{2}$ The 2011 World Alzheimer report concluded 'there is strong evidence to support cognitive stimulation programmes and these interventions should therefore be routinely offered'. ${ }^{3}$ Cognitive stimulation is a psychological intervention for dementia that targets cognitive and social functioning and is designed to enhance general cognitive abilities. Cognitive stimulation therapy (CST) is a well-defined evidence-based version of cognitive stimulation that is standardised, including two training manuals and a DVD. ${ }^{4}$ Cognitive stimulation therapy was developed following review of a related approach known as reality orientation ${ }^{5}$ and evaluated CST in a pilot trial, ${ }^{6}$ followed by a full trial, ${ }^{4}$ and developed a manual ${ }^{7}$ and a training DVD. It is now used widely across the UK and in several other countries. A pilot study of maintenance CST that continued for an extra 16 weekly sessions beyond the standard 7-week (14-session) CST programme ${ }^{8}$ found a significant improvement in cognitive function compared with CST alone. The Cochrane review found no link between duration or frequency of the programme and degree of improvement. ${ }^{2}$ Some studies have continued cognitive stimulation for 6 months or more, ${ }^{9,10}$ but there is little evidence about how far potential benefits may continue after sessions end. The Cochrane review suggested that after the sessions finished the effects on cognition were evident for at most 3 months; ${ }^{2}$ and another study found no continuing effects at 10 months. ${ }^{11}$ Our trial aimed to evaluate the effectiveness of maintenance CST in improving cognition and quality of life in people with dementia who have completed the standard CST programme. Hence, the intervention group would continue with maintenance CST, whereas the control group would have standard CST only, followed by treatment as usual (TAU). ${ }^{12}$ In addition, a substudy focused on the effects of maintenance CST on people with dementia taking AChEIs.

\section{Method}

\section{Study design}

This was a single-blind, multicentre, pragmatic randomised controlled trial (RCT) comparing maintenance CST groups after completing standard CST v. standard CST only followed by TAU. ${ }^{13}$ There was no modification in design or eligibility criteria from the study protocol (full details available in Aguirre et $a l^{12}$ ). The clinical trial registration number is ISRCTN26286067.

\section{Participants}

Potential centres were screened for eligibility to determine whether there were sufficient numbers of potential participants with dementia, using the inclusion criteria flow chart. Participants all met DSM-IV criteria for dementia ${ }^{14}$ using the diagnostic algorithm and most had either Alzheimer's disease or vascular dementia. All had mild (45\%) to moderate dementia (55\%) on the Clinical Dementia Rating scale; ${ }^{15}$ could communicate, hear and see well enough to participate in the group; had no major physical illness or disability, or diagnosed intellectual disability. 
All trial participants completed 7 weeks of $\mathrm{CST}^{4}$ comprising 14 twice-weekly $45 \mathrm{~min}$ sessions according to the CST manual. ${ }^{7}$

Approximately half of the participants were from nine care homes and half from nine community services within London, Essex and Bedfordshire. The community centres included four voluntary sector specialist dementia day centres and five centres based in local community mental health teams for older people. The nine care homes included five provided by Social Services, one by the private sector, and three by a voluntary organisation. Of 21 centres approached, 1 refused and 2 had too few eligible participants. The study was approved by the Barking \& Havering Local Research Ethics Committee in October 2008 (ethical approval reference number: 08/H0702/68).

\section{Intervention}

After completion of the CST programme participants were randomised within each centre to either the intervention group 24-week maintenance CST programme (maintenance CST group $)^{16}$ or the TAU group. Treatment as usual varied across the 18 centres but other activities were generally available to both groups.

The maintenance CST programme was based on the theory of cognitive stimulation as applied to the original CST programme ${ }^{4}$ guided by the Medical Research Council framework for complex interventions. ${ }^{17,18}$ Each maintenance CST session has a specific theme or activity (for example current affairs, my life, word games) within a consistent structure including orientation-based activity, refreshments and a group song. Each group had two facilitators, one from the research team and one staff member from the participating centre (i.e. care home or community service). All facilitators had at least 1 year of experience in dementia care, and had attended the 1-day CST training course.

\section{Outcome measures}

Participants were interviewed at baseline, before randomisation, at 3 months (intermediate end-point) and after 6 months (primary end-point). Researchers collected the proxy ratings of the quality of life measures, the Neuropsychiatric Inventory (NPI $)^{19}$ and the Alzheimer's Disease Cooperative Study - Activities of Daily Living (ADCS-ADL $)^{20}$ in structured interviews: with staff for participants in care homes; and with family carers for those in the community.

\section{Primary outcomes}

(a) Alzheimer's Disease Assessment Scale - Cognition Subscale (ADAS-Cog). This is the standard cognitive test used in clinical trials for dementia. ${ }^{21}$ This comprises 11 tasks measuring memory, language, praxis, attention and other cognitive abilities. Lower scores reflect better cognition.

(b) Quality of Life in Alzheimer's Disease scale (Qol-AD). ${ }^{22}$ This is recommended by the European consensus on outcome measures for psychosocial interventions in dementia. ${ }^{23}$ The Qol-AD includes both self-rating and proxy rating (by family care or staff) versions and covers 13 domains of quality of life. It has good internal consistency, validity and reliability. Higher scores reflect better quality of life.

\section{Secondary outcomes}

(a) Mini-Mental State Examination (MMSE). A brief but widely used generic test of cognitive function, with higher scores indicating better cognition. ${ }^{24}$ This is easier to complete than the ADAS-Cog, but still has good reliability and validity.

(b) Dementia Quality of Life scale (DEMQOL). ${ }^{25}$ The DEMQOL covers five domains of quality of life and uses both selfreporting and rating by family carer or staff member as proxy, with higher scores indicating better quality of life. It has good internal consistency, interrater reliability and concurrent validity and can generate a measure of utility.

(c) Neuropsychiatric Inventory. ${ }^{19}$ This assesses ten behaviours that commonly occur in dementia and has good validity and reliability. Lower scores on this specific measure reflect better behaviour. Total score is the sum of frequency severity of each behaviour.

(d) Alzheimer's Disease Cooperative Study - Activities of Daily Living. This validated questionnaire assesses functional capacity over the range of dementia severity. ${ }^{20}$ By summing competencies this measure gives high scores to more able respondents.

\section{Sample size}

Based on the Cochrane review we estimated an effect size for maintenance CST of 0.39 on the ADAS-Cog with power of $80 \%$ when using a $5 \%$ significance level and estimating attrition at $15 \%$ between baseline and 6 months. This required a sample size of 230 participants randomised at baseline and an estimated 195 at follow-up. With an estimated 60 participants with Alzheimer's disease and taking AChEIs, this provided sufficient numbers for the maintenance CST/AChEIs substudy to estimate effect size and the feasibility of a full-scale trial.

\section{Randomisation}

All participants completed the initial CST programme ${ }^{13}$ and were then allocated at random between (a) the intervention group receiving weekly maintenance CST for 24 weeks (maintenance CST group) or (b) the control group receiving TAU (TAU group). The North Wales Organisation for Randomised Trials in Health (NWORTH) clinical trials unit remotely randomised participants in equal proportions between groups after stratifying for: centre (community service or care home), whether AChEI was prescribed, and previous CST group (www.bangor.ac.uk/imscar/ nworth/). The random allocation sequence was computergenerated and in the ratio of $1: 1$. The NWORTH clinical trials unit emailed the individual allocation to the site researcher delivering the intervention and stored the allocation list under a secure password, which was not available to any study site staff. The scheduled treatment sessions, session records and participant records were saved at the site, strictly separated, and distant from the coordinating study centre. Once the trial was completed in each centre, records were transferred to the coordinating study centre and stored by the study centre administrator who was not involved in the assessment process or data analysis. This was to avoid contamination. The nature of the intervention prevented us from masking participants to their allocated group. However, masked researchers conducted initial and subsequent interviews, generally in care homes or participants' own homes. The statistician conducting the data analysis was also masked to group assignment.

\section{Statistical analysis}

We used the MACRO system (version 3.0.84 on Windows 2003 R2; Infermed, London, UK, www.infermed.com) to manage the data. Data was entered manually and audited internally for typing errors by hand, to ensure a low error rate. Data were transferred to SPSS version 20 on Windows 7 and audited externally by NWORTH with hard copies of assessments. These audits entailed cross-checking a random $10 \%$ sample of the electronic data with the paper records to ensure accurate entry. Both random and systematic data entry errors were identified and corrected. As 
the audits were carried out in parallel with data entry, systematic errors could be corrected at an early stage. The data-set is available from the authors on request.

Participants' consent was obtained, but the data presented are anonymised and risk of identification is low. For participants with some follow-up data, we imputed individual data missing within a scale according to the validated rules for that scale; and missing total scores by multiple regression on variables including allocated group, age, gender, ethnicity, marital status, whether prescribed an AChEI, staff or family caregiver, centre type and individual centre (using random effects). We adopted a forward stepwise model, and used baseline scores to help predict scores at 3 months, then both of these to predict scores at 6 months, since no participant missing at 3 months returned at 6 months.

Primary analyses by treatment allocated used analysis of covariance to adjust all imputed data for baseline differences in age, gender, ethnicity, marital status, prescription of AChEIs, proportion of family caregivers, individual centre (using random effects) and baseline score on the variable under analysis. We then estimated the effect of treatment from the resulting model. The maintenance CST/AChEIs trial platform followed the same methodology as for the primary analysis and used the interaction term between AChEIs and the treatment group to identify any effect between the two factors for the outcome measures.

\section{Results}

The recruitment period took place between January 2009 and September 2010. The final 24-week follow-up was completed in May 2011. Of 272 people with dementia that started the CST groups and were considered for the trial, 36 were withdrawn
Table 1 Potential participants at baseline and reasons for withdrawal

\begin{tabular}{|lc|}
\hline Participants at baseline 0: before start of CST groups, $n$ & 272 \\
\hline Total lost from the beginning of CST groups, $n$ & 36 \\
\hline Reason for withdrawal, $n$ (\%) & $17(47)$ \\
Did not like CST groups and wanted to withdraw & $15(42)$ \\
Health issues & $2(6)$ \\
Difficulties with group time or other participants & $2(6)$ \\
Moved to a different care home & 236 \\
\hline Participants at baseline 1 - after completion of CST groups, $n$ & \\
\hline
\end{tabular}

(Table 1). We followed up 218 participants (92\% of 236; $96 \%$ of those still alive) at 3 months and 199 (84\% of 236 ; $89 \%$ of those still alive) at 6 months. The CONSORT flow chart (Fig. 1) records the reasons for subsequent withdrawals. The withdrawal rate was similar in both arms of the trial. Of the 236 participants, 123 were allocated to the maintenance CST group and 113 to usual care (TAU group). The groups were well matched at baseline and randomisation avoided imbalances (Table 2). The mean age was 83 years and most participants were White females. On average participants allocated to the maintenance CST group attended 18 of the 24 available sessions.

\section{Outcomes}

At the 6-month primary end-point (Table 3), the maintenance CST group had higher scores than the TAU group on self-rated QoL-AD (first primary outcome) that reached statistical significance, with a mean difference of 1.78 ( $95 \% \mathrm{CI}-0.01$ to $3.57, P=0.03)$.

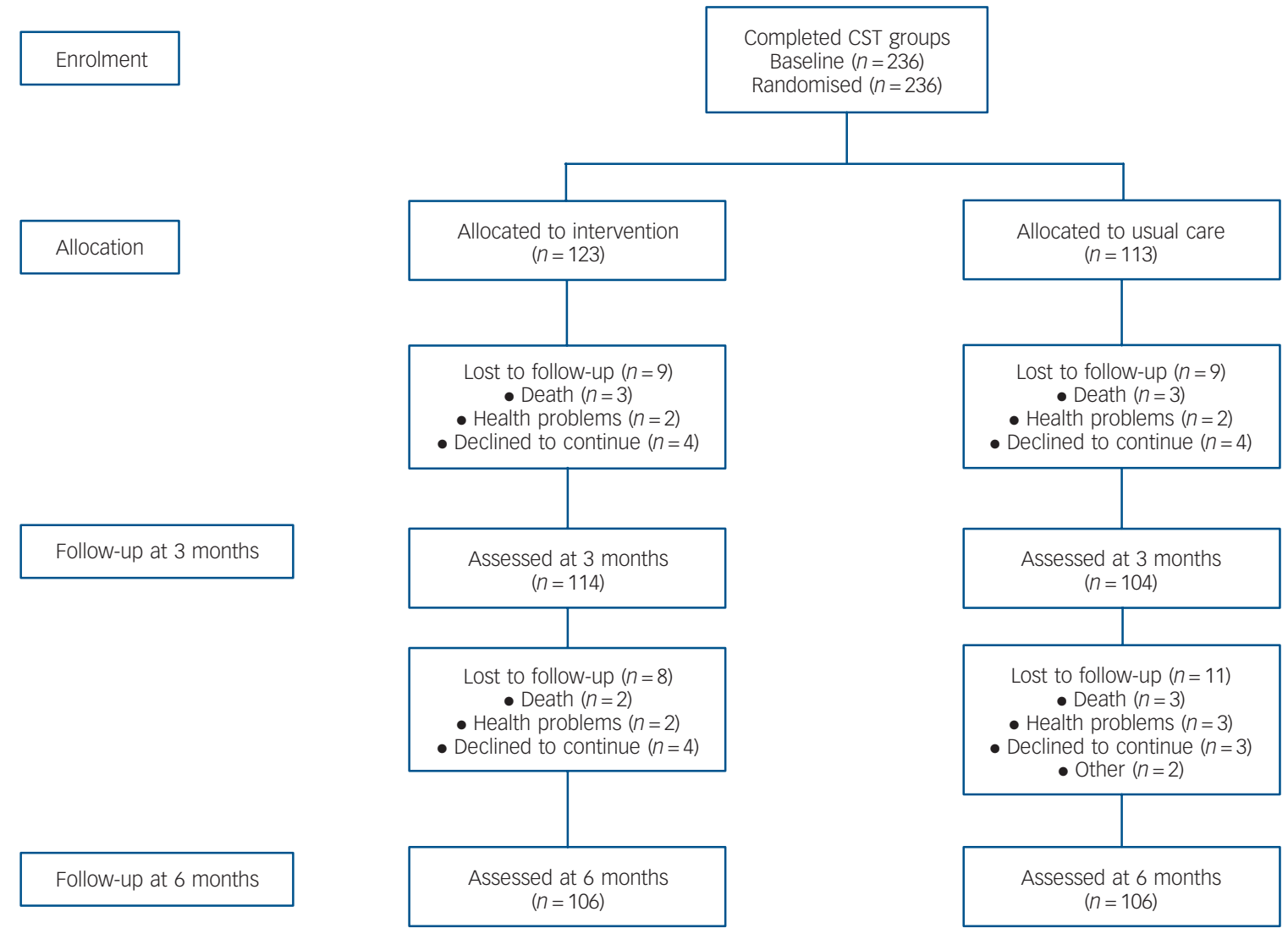

Fig. 1 Consort flow chart of participants' progress.

CST, cognitive stimulation therapy. 


\begin{tabular}{|c|c|c|c|c|}
\hline \multirow[b]{2}{*}{ Characteristics } & \multicolumn{2}{|c|}{$\begin{array}{l}\text { Maintenance cognitive stimulation therapy group } \\
\qquad(n=123)\end{array}$} & \multicolumn{2}{|c|}{$\begin{array}{l}\text { Treatment as usual group } \\
\qquad(n=113)\end{array}$} \\
\hline & $n(\%)$ & Mean (s.d.) & $n(\%)$ & Mean (s.d.) \\
\hline Female & $80(65)$ & & $70(62)$ & \\
\hline Ethnicity: White & $111(90)$ & & $104(92)$ & \\
\hline Marital status: widow & $54(44)$ & & $57(50)$ & \\
\hline Dementia diagnosis: Alzheimer's disease & $38(31)$ & & $35(31)$ & \\
\hline On acetylcholinesterase inhibitors & $42(34)$ & & $34(30)$ & \\
\hline In care home & $51(41)$ & & $50(44)$ & \\
\hline Age, years & & $82.7(7.9)$ & & $83.5(7.2)$ \\
\hline Alzheimer's Disease Assessment Scale - Cognition Subscale & & $31.1(14.6)$ & & $33.2(13.0)$ \\
\hline Quality of Life in Alzheimer's Disease scale & & $36.1(4.8)$ & & $36.5(5.7)$ \\
\hline Mini-Mental State Examination & & $17.8(5.6)$ & & $17.8(5.4)$ \\
\hline Dementia Quality of Life scale & & $94.8(10.9)$ & & $95.1(11.7)$ \\
\hline Neuropsychiatric Inventory & & $13.8(12.9)$ & & $11.3(9.1)$ \\
\hline $\begin{array}{l}\text { Alzheimer's Disease Cooperative Study - } \\
\text { Activities of Daily Living scale }\end{array}$ & & $42.7(17.2)$ & & $41.5(18.1)$ \\
\hline Proxy Quality of Life in Alzheimer's Disease scale & & $33.7(5.9)$ & & $33.3(4.9)$ \\
\hline Proxy Dementia Quality of Life scale & & $102.2(13.5)$ & & $102.2(11.2)$ \\
\hline
\end{tabular}

There were no significant differences on ADAS-Cog (second primary outcome). There were no significant differences in secondary outcomes at 6 months. There were two types of centre studied, care homes and community services. There were significant differences among the centres over and above that explained by centre type.

At 3 months there were no significant differences on either primary outcome. For secondary outcomes, participants randomised to the maintenance CST group had significantly better scores than those in the TAU group on proxy ratings of quality of life (QoL-AD and DEMQOL) and daily activities. The mean difference on the proxy QoL-AD was 1.53 (95\% CI $0.37-2.69, P=0.01$ ); and for the proxy DEMQOL it was 3.24 (95\% CI 0.29-6.19, $P=0.03$ ). The difference on the ADCS-ADL was 2.64 (95\% CI $0.08-5.20$, $P=0.04)$.

\section{Quality of maintenance CST programme provision}

To estimate the quality of the maintenance CST provision after each session the researchers made ratings on a range of factors related to the successful running of the groups: manager's attitude $(0-2)$, centre atmosphere $(0-2)$, cofacilitators input $(0-2)$, group atmosphere (0-2) and average number of sessions attended by participants $(0$, less than $12 ; 1,13-20 ; 2,21-24)$, with higher scores indicating better quality. Centres were divided into low quality (score 0-5) and high quality (score 6-10). Eight out of nine community centres scored as high quality compared with only six out of nine care homes. The quality indicator was incorporated into the model of analysis with primary outcome results, with baseline score, centre type, age and allocation as a fixed effect and within a random effect of centre nested within the interaction of quality and type. The analysis showed that both centre type and quality of CST provision were not significant in the model using either QoL-AD or ADAS-Cog. There were differences among the centres that could not be explained by amount of sessions attended or quality of CST provision.

\section{Maintenance CST/AChEI trial platform results}

There were no significant results in relation to primary outcomes. Table 4 shows the observed means and standard deviations at baseline. The means and standard deviations presented at the first and second follow-ups are adjusted for the factors and covariates in the fitted model including the treatment group $\times$ AChEIs interaction term. The follow-up means are standardised to a

\begin{tabular}{|c|c|c|c|c|c|c|c|c|}
\hline \multirow[b]{2}{*}{$\begin{array}{l}\text { Adjusted } \\
\text { outcomes }\end{array}$} & \multicolumn{4}{|c|}{ Primary end-point - 6-month follow-up } & \multicolumn{4}{|c|}{ Secondary end-point - 3-month follow-up } \\
\hline & $\begin{array}{l}\text { Maintenance } \\
\text { CST group } \\
\text { Mean (s.e.) }\end{array}$ & $\begin{array}{l}\text { TAU group } \\
\text { Mean (s.e.) }\end{array}$ & $\begin{array}{l}\text { Difference } \\
\text { mean } \\
(95 \% \mathrm{Cl})^{\mathrm{a}}\end{array}$ & $\begin{array}{c}P, \text { median } \\
\text { of } \\
5 \text { imputations }\end{array}$ & $\begin{array}{l}\text { Maintenance } \\
\text { CST group } \\
\text { Mean (s.e.) }\end{array}$ & $\begin{array}{l}\text { TAU group } \\
\text { Mean (s.e.) }\end{array}$ & $\begin{array}{l}\text { Difference } \\
\text { mean } \\
(95 \% \mathrm{Cl})^{\mathrm{a}}\end{array}$ & $\begin{array}{c}P, \text { median } \\
\text { of } \\
5 \text { imputations }\end{array}$ \\
\hline ADAS-Cog ${ }^{b}$ & $35.94(2.79)$ & $35.29(2.85)$ & $-0.65(-3.71$ to 2.42$)$ & 0.67 & $35.32(2.56)$ & $34.47(2.59)$ & $-0.85(-3.40$ to 1.70$)$ & 0.27 \\
\hline QoL-ADC & $35.62(1.43)$ & $33.84(1.53)$ & $1.78(-0.01$ to 3.57$)$ & 0.03 & 34.29 (1.03) & 33.97 (1.04) & $0.32(-0.88$ to 1.52$)$ & 0.54 \\
\hline MMSE $^{\mathrm{C}}$ & $16.34(1.21)$ & $15.49(1.25)$ & $0.85(-0.29$ to 1.99$)$ & 0.15 & $16.09(0.88)$ & $15.79(0.91)$ & $0.30(-0.72$ to 1.31$)$ & 0.56 \\
\hline DEMQOL $^{\mathrm{C}}$ & $89.13(3.55)$ & $88.83(3.56)$ & $0.30(-2.70$ to 3.31$)$ & 0.87 & $89.85(2.34)$ & $90.71(2.38)$ & $-0.86(-3.45$ to 1.73$)$ & 0.54 \\
\hline$N P I^{b}$ & $18.76(3.78)$ & $20.35(3.94)$ & $1.58(-2.67$ to 5.84$)$ & 0.53 & $14.71(2.84)$ & $16.18(2.76)$ & $1.47(-1.59$ to 4.53$)$ & 0.34 \\
\hline$A D C S-A D L^{C}$ & $43.29(2.88)$ & $42.35(2.87)$ & $0.94(-2.04$ to 3.92$)$ & 0.54 & 43.58 (2.32) & $40.94(2.32)$ & 2.64 (0.08 to 5.20$)$ & 0.04 \\
\hline Proxy QoL-ADC & $34.12(1.41)$ & 34.05 (1.41) & $0.07(-1.39$ to 1.53$)$ & 0.95 & $33.93(1.05)$ & $32.40(1.07)$ & 1.53 (0.37 to 2.69$)$ & 0.01 \\
\hline Proxy DEMQOL ${ }^{\mathrm{C}}$ & 97.75 (3.23) & $96.61(3.21)$ & $1.13(-2.24$ to 4.51$)$ & 0.50 & $101.36(2.67)$ & 98.12 (2.67) & 3.24 (0.29 to 6.19) & 0.03 \\
\hline \multicolumn{9}{|c|}{$\begin{array}{l}\text { TAU, treatment as usual; ADAS-Cog, Alzheimer's Disease Assessment Scale - Cognition Subscale; QOL-AD, Quality of Life in Alzheimer's Disease scale; MMSE, Mini-Mental State } \\
\text { Examination; DEMQOL, Dementia Quality of Life scale; NPI, Neuropsychiatric Inventory; ADCS-ADL, Alzheimer's Disease Cooperative Study - Activities of Daily Living scale. } \\
\text { a. Positive differences favour maintenance CST. } \\
\text { b. Lower scores show better outcome. } \\
\text { c. Higher scores show better outcome. }\end{array}$} \\
\hline
\end{tabular}


common baseline mean value. The significance levels quoted below are for the interaction term. Only for MMSE at both 3 and 6 months follow-up were significant interactions found. The results show that starting from a mean baseline MMSE of 17.8 there was the smallest decrease to $17.25(95 \%$ CI $14.63-19.87, P=0.03)$ at the second follow-up in those taking $\mathrm{AChEI}$ and receiving maintenance CST. The largest decrease occurred in those taking AChEIs but with no maintenance CST where the mean was 14.62 (95\% CI $11.81-17.43, P=0.03$ ). There were no other significant differences between groups in any other outcome measures.

Between baseline and second follow-up, $92 \%$ had no changes to their AChEI status with 3 participants stopping ( 1 in the TAU group and 2 in the maintenance CST group) and 11 starting (4 in the TAU group and 7 in the maintenance CST group) medication. There were no differences between the groups (intervention and control) in the number of reported adverse events or severity. In the maintenance CST group there were five deaths and four withdrawals because of health issues. In the TAU group there were six deaths and five withdrawals because of health issues. All events were judged to be unrelated to trial treatment or assessment contacts by the study trial coordinator and principal investigator.

\section{Discussion}

\section{Main findings}

Cognitive stimulation for people with dementia is recognised as being effective $e^{2,13}$ and cost-effective, ${ }^{26}$ and CST in particular improves both cognition and quality of life. ${ }^{4,13}$ This trial found that after the initial CST programme, a further 24-week course of weekly maintenance CST improved quality of life at 6-month follow-up but conferred no additional benefit to cognition. At 6 months it was only the participants who reported an improved quality of life (a small standardised difference of 0.35), whereas at 3 months it was only the proxy respondents (carers/care staff) that noted the improvement (a small standardised difference of 0.30). Participants in the intervention group also improved in their activities of daily living at 3 months (a very small standardised difference of 0.15). There were no significant differences in other outcomes at either 3 or 6 months.

The substudy results suggest that people on AChEI medication may benefit cognitively from maintenance CST, suggesting a synergistic effect. This is in line with other studies combining AChEIs and cognitive stimulation, ${ }^{4,8,13}$ and the Cochrane review ${ }^{2}$ that found that the effect of cognitive stimulation on cognition is over and above the effects of medication alone. The relevance in terms of clinically significant change is less clear. A mean decrease of 1 v. 4 points on the MMSE scale may make a big difference for some people with dementia. The difference might translate into economic benefits since a difference of 1 point in the MMSE score may be associated with substantial reductions in the costs of caring for people with dementia. ${ }^{27}$ The CST programme prior to baseline resulted in mean improvements of 4.4 points on the ADAS-Cog and 2.7 points on the MMSE. ${ }^{13}$ Since dementia is associated with progressive cognitive decline there may have

\begin{tabular}{|c|c|c|c|c|c|c|c|c|c|}
\hline & \multirow[b]{2}{*}{$n$} & \multicolumn{2}{|l|}{ Baseline } & \multicolumn{2}{|l|}{3 months } & \multicolumn{4}{|c|}{6 months } \\
\hline & & Mean $(95 \% \mathrm{Cl})$ & s.e. & $\begin{array}{l}\text { Model adjusted } \\
\text { Mean }(95 \% \mathrm{Cl})\end{array}$ & s.e. & $\begin{array}{c}\text { Interaction } \\
P\end{array}$ & $\begin{array}{l}\text { Model adjusted } \\
\text { Mean }(95 \% \mathrm{Cl})\end{array}$ & s.e. & $\begin{array}{c}\text { Interaction } \\
P\end{array}$ \\
\hline ADAS-Cog & & & & & & 0.13 & & & 0.71 \\
\hline AChEl & 34 & 31.29 (27.17-35.41) & 2.09 & 37.05 (31.23-42.87) & 2.84 & & 36.52 (29.47-43.58) & 3.53 & \\
\hline TAU & 79 & 34.03 (31.08-36.99) & 1.50 & 32.35 (26.77-37.92) & 2.68 & & 34.67 (28.81-40.52) & 2.97 & \\
\hline AChEl/MCST & 42 & $28.65(25.14-32.16)$ & 1.78 & $36.55(29.94-43.16)$ & 3.16 & & $35.77(29.33-42.22)$ & 3.28 & \\
\hline MCST & 81 & 32.4 (28.91-35.89) & 1.77 & $33.85(28.47-39.22)$ & 2.57 & & 35.99 (30.07-41.91) & 2.98 & \\
\hline QOL-AD & & & & & & 0.97 & & & 0.48 \\
\hline AChEl & 34 & $37.73(36.24-39.22)$ & 0.76 & 32.81 (30.4-35.22) & 1.23 & & $33.94(30.23-37.65)$ & 1.86 & \\
\hline TAU & 79 & 35.99 (34.64-37.34) & 0.69 & 35.13 (32.98-37.27) & 1.09 & & 33.81 (30.83-36.79) & 1.52 & \\
\hline AChEI/MCST & 42 & $37.08(35.56-38.6)$ & 0.77 & $33.14(30.66-35.63)$ & 1.27 & & 34.72 (31.39-38.06) & 1.70 & \\
\hline MCST & 81 & $35.62(34.58-36.67)$ & 0.53 & 35.45 (33.39-37.5) & 1.05 & & 36.07 (33.25-38.89) & 1.44 & \\
\hline NPI & & & & & & 0.99 & & & 0.26 \\
\hline AChEl & 34 & $12.13(8.94-15.32)$ & 1.62 & 17.23 (10.77-23.69) & 3.28 & & 23.78 (14.85-32.71) & 4.54 & \\
\hline TAU & 79 & $11.00(9.01-12.99)$ & 1.01 & $15.12(9.51-20.74)$ & 2.86 & & $17.15(9.08-25.23)$ & 4.11 & \\
\hline MCST/AChEI & 42 & $16.15(10.77-21.53)$ & 2.73 & $15.85(9.17-22.53)$ & 3.39 & & $18.21(9.44-26.98)$ & 4.47 & \\
\hline MCST & 81 & $12.65(10.58-14.72)$ & 1.05 & $13.61(8.03-19.19)$ & 2.82 & & 17.49 (10.05-24.93) & 3.79 & \\
\hline ADCS-ADL & & & & & & 0.80 & & & 0.80 \\
\hline AChEl & 34 & $44.03(38.35-49.71)$ & 2.88 & 41.51 (36.04-46.98) & 2.79 & & 42.45 (35.9-49.00) & 3.34 & \\
\hline $\mathrm{TAU}$ & 79 & $40.42(36.28-44.56)$ & 2.10 & 40.37 (35.53-45.22) & 2.47 & & $42.22(36.26-48.17)$ & 3.04 & \\
\hline MCST/AChEI & 42 & 48.24 (42.59-53.89) & 2.87 & $43.83(38.21-49.45)$ & 2.87 & & $43.91(37.12-50.69)$ & 3.46 & \\
\hline MCST only & 81 & 39.78 (36.32-43.23) & 1.75 & 43.17 (38.59-47.75) & 2.34 & & 42.91 (37.18-48.64) & 2.92 & \\
\hline MMSE & & & & & & 0.03 & & & 0.03 \\
\hline AChEl & 34 & $18.85(17.29-20.41)$ & 0.79 & $15.26(13.13-17.39)$ & 1.08 & & $14.62(11.81-17.43)$ & 1.40 & \\
\hline TAU & 79 & $17.33(16.08-18.58)$ & 0.63 & $16.25(14.44-18.05)$ & 0.92 & & $16.26(13.68-18.84)$ & 1.28 & \\
\hline MCST/AChEI & 42 & $18.27(16.62-19.91)$ & 0.84 & $17.17(15.09-19.25)$ & 1.06 & & $17.25(14.63-19.87)$ & 1.33 & \\
\hline MCST & 81 & 17.55 (16.29-18.8) & 0.64 & $15.77(14.03-17.50)$ & 0.88 & & $16.26(13.71-18.8)$ & 1.26 & \\
\hline DEMQOL & & & & & & 0.92 & & & 0.97 \\
\hline AChEl & 34 & 97.90 (94.93-100.87) & 1.51 & $89.13(83.62-94.65)$ & 2.81 & & 87.93 (80.00-95.87) & 3.90 & \\
\hline TAU & 79 & $93.86(91.07-96.66)$ & 1.42 & $92.25(87.33-97.17)$ & 2.51 & & $89.75(82.03-97.46)$ & 3.74 & \\
\hline AChEI/MCST & 42 & $97.36(94.35-100.36)$ & 1.53 & 88.99 (83.33-94.66) & 2.89 & & 87.88 (80.13-95.62) & 3.86 & \\
\hline MCST & 81 & 93.49 (91.02-95.97) & 1.26 & $91.04(86.4-95.68)$ & 2.37 & & $90.22(82.54-97.9)$ & 3.69 & \\
\hline
\end{tabular}

ADAS-Cog, Alzheimer's Disease Assessment Scale - Cognition Subscale; TAU, treatment as usual; MCST, maintenance CST; QoL-AD, Quality of Life in Alzheimer's Disease Scale; NPI, Neuropsychiatric Inventory; ADCS-ADL, Alzheimer's Disease Cooperative Study - Activities of Daily Living scale; MMSE, Mini-Mental State Examination; DEMQOL, Dementia 
been limited potential for further cognitive improvement with the maintenance programme. This means that at 6-month follow-up both groups were likely to have declined from the baseline taken after the CST groups finished, and so significant differences in cognition were only likely to be found if the usual care (CST only) group had declined more than the maintenance group.

\section{Strengths and limitations}

As participants came from nine care homes and nine community services across London, Essex and Bedfordshire, this pragmatic trial is likely to be generalisable in many respects. However, since participants were almost all White it is hard to say how far CST is useful for other ethnic or cultural groups. Nevertheless, we have recently adapted the CST programme for a south Asian population and successfully run a local group in Hindi and Gujarati. Although we took great care to mask our researchers to allocated treatment, we could not mask those care staff and family carers who provided proxy ratings for four measures (ADCS-ADL, NPI, QoL-AD and DEMQOL) and this means there is a risk of detection bias. Notably these measures provided three of the four significant findings. Compared with the original CST study this trial had more diversity in dementia severity as a result of a much higher proportion being recruited from the community $(50 \% v .15 \%)$. This resulted in the standard deviations of the cognitive measures being much higher than in the original trial of CST. ${ }^{4}$ A larger trial might find significant differences in cognition after weekly maintenance CST. However, it may be that more frequent groups would be more efficacious. This was the first rigorous trial of maintenance CST. The results are encouraging but not conclusive and suggest that further trials are needed and it will be important for other groups to evaluate maintenance $\mathrm{CST}^{28}$

Future research could look in more depth at the optimum frequency and duration of CST groups, for example to continue to provide CST twice a week (rather than once weekly) for a 6-month period. Another option would be to repeat the standard 7-week CST programme after a 4-month break. However, this option could be disruptive to the groups, and would not mirror the standard approach used in drug interventions that are given without interruption rather than as a short course.

\section{Clinical implications}

In the previous stage of this study before and after CST (prior to randomisation) we found that both cognition and quality of life significantly improved, including for those people on AChEIs. ${ }^{13}$ However, following maintenance CST at 6-month follow-up we found no significant differences in cognition. There were no differences on the ADAS-Cog, although the MMSE showed a 0.85 points advantage for the maintenance CST group. This does not suggest that maintenance CST has substantial effects on cognition over and above the original benefits of the initial CST programme. ${ }^{2}$ Generally, MMSE scores in mild to moderate dementia decrease by 2 to 4 points per year. ${ }^{29}$ Before the initial CST programme ${ }^{13}$ ( 2 months before the start of this RCT) the mean ADAS-Cog was 35.0 and the mean MMSE score was 15.8 . Eight months later, at 6-month follow-up, there was no overall cognitive decline with the mean ADAS-Cog scores being 35.9 and 35.3 and the mean MMSE scores being 16.3 and 15.5 in the intervention and control groups respectively. From a standardised baseline score of 17.8 on the MMSE, in the AChEI only group, MMSE scores fell to 14.6 points in the 6 months of the maintenance CST trial compared with a decrease to 17.3 in the maintenance CST/AChEI (combined) treatment, and a decrease to 16.3 in the maintenance CST only group. This suggests that CST may continue to have some degree of protective effect on cognition over and above the effects of medication. Other studies using usual care control groups have also found that a programme of cognitive stimulation sessions over a longer time period can be effective in reducing cognitive decline in dementia. ${ }^{30,31}$

In chronic conditions quality of life may be more important for older adults than disease-specific outcomes and it is a key outcome that interventions for dementia should target. Benefits to cognition alone may not be sufficient to justify an extensive programme of intervention unless they are accompanied by other benefits such as quality of life. ${ }^{32}$ Two recent systematic reviews highlighted that there are few well-designed studies on the effectiveness of either pharmacological ${ }^{33}$ or psychosocial $^{34}$ interventions on quality of life. Like other follow-up studies we found that individual changes in quality of life were apparent for nearly three-quarters of our sample. ${ }^{35-37}$ In contrast to the Cochrane review of cognitive stimulation our study found that activities of daily living improved at 3-month follow-up. However, previous research $^{35}$ suggests that there may be a correlation between proxy-rated quality of life and activities of daily living. It might be that the effects of the intervention on proxy-rated quality of life was linked with the effects on activities of daily living. At 6-month follow-up these proxy-rated domains showed no difference. However, for the person with dementia a temporary improvement in quality of life, cognition or activities of daily living may all be considered worthwhile.

\section{Future research}

As this was the first rigorous trial of maintenance CST, we encourage others to implement and evaluate this novel extension in other populations, in other contexts with other staff. In our research programme we have three further cognitive stimulation therapy studies. ${ }^{28}$ First, we are undertaking a pragmatic cluster randomised implementation trial to compare staff trained in CST receiving either additional support (internet support, regular telephone support) or no support. This will evaluate whether additional staff support results in more CST group attendances. Second, we are conducting an implementation in practice study measuring minimal outcomes (cognition and quality of life) for centres running CST/maintenance CST groups. Finally, we have developed a version of CST for use by the family carer (individual CST) and this is currently being evaluated in a large multicentre trial funded by the National Institute of Health Research/Health Technology Assessment programme. ${ }^{38}$

In conclusion, standard CST can improve cognition and quality of life. ${ }^{39}$ This trial indicates that weekly maintenance CST over 24 weeks provides some potential benefit beyond the basic CST programme. Further research should evaluate whether long-term CST should be provided more frequently than once a week. Over the 8 months (from the original baseline before 2 months of CST and the 6-month follow-up), the average cognitive decline in both the maintenance CST and TAU groups was considerably less than would normally be expected in practice suggesting the original CST programme had some residual beneficial effect. Maintenance CST may offer short- and long-term benefits to quality of life. The substudy of maintenance CST with AChEIs provides initial evidence that maintenance CST in combination with AChEI medication may have longer-term benefits to cognition. Pharmacological and psychosocial interventions may potentially work better together than either alone. 
Martin Orrell, PhD, Elisa Aguirre, PhD, Unit of Mental Health Sciences, University College London, and Research and Development Department, North East London Foundation Trust, Goodmayes Hospital, ॥lford; Aimee Spector, PhD, Research and Development Department, North East London Foundation Trust, Goodmayes Hospital, Ifford, and Research Department of Clinical, Educational and Health Psychology, University College London; Zoe Hoare, PhD, North Wales Organisation for Randomised Trials in Health (NWORTH), Institute of Medical \& Social Care Research, Bangor; Robert T. Woods, MSC, DSDC Wales, Bangor University, Bangor; Amy Streater, MSc, Unit of Mental Health Sciences, University College London, and Research and Development Department, North East London Foundation Trust, Goodmayes Hospital, llford; Helen Donovan, PSyD, Clinical Psychology Service, South Essex Partership NHS Foundation Trust, Bedford; Juanita HOe PhD, Unit of Mental Health Sciences, University College London, and Research and Development Department, North East London Foundation Trust, Goodmayes Hospital, Ifford; Martin Knapp, PhD, Personal Social Services Research Unit, London School of Economics and Political Science; Christopher Whitaker, MSc, North Wales Organisation for Randomised Trials in Health (NWORTH), Institute of Medical \& Social Care Research, Bangor; Ian Russell, PhD, Swansea University, College of Medicine, Singleton Park, Swansea, UK

Correspondence: Martin Orrell, Unit of Mental Health Sciences, University College London, Charles Bell House, 67-73 Riding House Street, London W1W 7EJ, UK. Email: m.orrell@ucl.ac.uk

\section{Funding}

Maintenance Cognitive Stimulation Programme (ISRCTN26286067) is part of the Support at Home - Interventions to Enhance Life in Dementia (SHIELD) project (Application No. RP-PG-0606-1083) awarded to M.O. (University College London (UCL)/North East London Foundation Trust), based in North East London Foundation Trust (study sponsor), and funded by the National Institute of Health Research (NIHR) Programme Grants for Applied Research funding scheme. Other grant holders include R.T.W. (Bangor), David Challis (Manchester), Esme Moniz-Cook (Hull), I.R. (Swansea), M.K. (LSE) and Georgina Charlesworth (UCL). This article presents independent research commissioned by the NIHR under its Programme Grants for Applied Research scheme (RP-PG-060-1083). The views expressed in this publication are those of the author(s) and not necessarily those of the National Health Service, the NIHR or the Department of Health. The NIHR Programme Grant for Applied Research scheme monitors progress of the programme RP-PG-060-1083 through regular reports. The NIHR encourages grant-holders to seek external peer-reviewed publication.

\section{Acknowledgements}

We would like to thank all the trial participants and their carers, especially for completing high proportion of responses; centre managers and staff for all their collaboration and support; a wide range of healthcare practitioners for generously referring participants to the trial; and the following researchers involved in data collection, entering the data and completing trial documentation - Lauren Yates, Kier Yong, Linda Smith, Stacie McCarry, Deepak Shankar and Caroline O'Haire.

\section{References}

1 Orrell M, Woods B, Spector A. Should we use cognitive stimulation therapy to improve cognitive function in people with dementia? BMJ 2012; 344: e633.

2 Woods B, Aguirre E, Spector A, Orrell M. Cognitive stimulation to improve cognitive functioning in people with dementia. Cochrane Database Syst Rev 2012; 2: CD005562.

3 Prince M, Bryce R, Ferri C. World Alzheimer Report: The Benefits of Early Diagnosis and Intervention. Alzheimer's Disease International, 2011 (www.alz.co.uk/worldreport2011).

4 Spector A, Thorgrimsen L, Woods B, Royan L, Davies S, Butterworth M, et al. Efficacy of an evidence-based cognitive stimulation therapy programme for people with dementia. Randomised controlled trial. Br J Psychiatry 2003; 183: $248-54$.

5 Spector A, Thorgrimsen L, Woods B, Orrell M. Reality orientation for dementia: a systematic review of the evidence of effectiveness from randomised controlled trials. Gerontologist 2000; 40: 206-12.

6 Spector A, Davies S, Woods B, Orrell M. Can reality orientation be rehabilitated? Development and piloting of an evidence-based programme of cognition-based therapies for people with dementia. Neuropsychol Rehabil 2001; 11: 377-97.

7 Spector A, Thorgrimsen L, Woods B, Orrell M. Making a Difference: An Evidence Based Group Programme to Offer Cognitive Stimulation Therapy (CST) to People With Dementia: Manual for Group Leaders. Hawker Publications, 2006

8 Orrell M, Spector A, Thorgrimsen L, Woods B. A pilot study examining the effectiveness of Maintenance Cognitive Stimulation Therapy (Maintenance CST) for people with dementia. Int J Geriatr Psychiatry 2005; 20: 446-51.
9 Buschert VC, Friese U, Teipel SJ, Schneider P, Merensky W, Rujescu D, et al. Effects of a newly developed cognitive intervention in amnestic mild cognitive impairment and mild Alzheimer's disease: a pilot study. J Alzheimers Dis 2011; 25: 679-94.

10 Requena C, Maestu F, Campo P, Fernandez A, Ortiz T. Effects of cholinergic drugs and cognitive training on dementia: 2-year follow up. Dement Geriatr Cogn Dis 2006; 22: 339-45

11 Chapman SB, Weiner MF, Rackley A, Hynan LS, Zientz J. Effects of cognitivecommunication stimulation for Alzheimer's disease patients treated with donepezil. J Speech Lang Hear Res 2004; 47: 1149-63.

12 Aguirre E, Spector A, Hoe J, Knapp M, Woods B, Orrell M, et al. Maintenance Cognitive Stimulation Therapy (CST) for dementia: a single-blind, multi-centre, randomised controlled trial of Maintenance CST vs. CST for dementia. Trials 2010; 11: 46 (http://www.trialsjournal. com/content/pdf/1745-6215-11-46.pdf).

13 Aguirre E, Hoare Z, Streater A, Spector A, Woods B, Hoe J, et al. Cognitive Stimulation Therapy (CST) for people with dementia - who benefits most? Int J Geriatr Psychiatry 2013; 28: 284-90.

14 American Psychiatric Association. Diagnostic and Statistical Manual of Mental Disorders (4th edn) (DSM-IV). APA 1994.

15 Hughes CP, Berg, L, Danziger WL, Coben LA, Martin RL. A new clinical scale for the staging of dementia. Br J Psychiatry 1982; 140: 566-72.

16 Aguirre E, Spector A, Hoe J, Streater A, Woods RT, Orrell M, et al. Development of an evidence-based extended programme of maintenance cognitive stimulation therapy (CST) for people with dementia. Nonpharmacol Ther Dement 2011; 1: 197-216.

17 Medical Research Council. A Framework for Development and Evaluation of RCTs for Complex Interventions to Improve Health. MRC, 2000.

18 Craig $\mathrm{P}$, Dieppe $\mathrm{P}$, MacIntyre S, Mitchie S, Nazareth I, Petticrew M. Developing and evaluating complex interventions: the new Medical Research Council guidance. BMJ 2008; 337: a1655.

19 Cummings L, Mega M, Gray K, Rosenberg-Thompson S, Carusi DA Gornbein J. The Neuropsychiatric Inventory: comprehensive assessment of psychopathology in dementia. Neurology 1994; 44: 2308-14.

20 Galasko D, Bennet D, Sano M, Ernesto C, Thomas R, Ferris S, et al. An inventory to assess activities of daily living for clinical trials in Alzheimer's disease: the Alzheimer Disease Cooperative Study. Alzheimer Dis Assoc Disord 1997; 11: S33-9.

21 Rosen WG, Mohs RC, Davis KL. A new rating scale for Alzheimer's disease. Am J Psychiatry 1984; 141: 1356-64.

22 Logsdon RG, Gibbons LE, McCurry SM, Teri L. Assessing quality of life in older adults with cognitive impairment. Psychosom Med 2002; 64: 510-9.

23 Moniz-Cook E, Vernooij-Dassen M, Woods R, Verhey F, Chattat R, Orrell M et al. A European consensus on outcome measures for psychosocial intervention research in dementia care. Aging Ment Health 2008; 12: $14-25$.

24 Folstein MF, Folstein SE, McHugh PR. Mini Mental State. A practical method for grading the cognitive state of patients for the clinician. J Psychiatr Res 1975; 12: 189-98.

25 Smith SC, Lamping DL, Banerjee S, Harwood R, Foley B, Knapp M, et al. Measurement of health-related quality of life for people with dementia: development of a new instrument (DEMQOL) and an evaluation of current methodology. Health Technol Assess 2005; 9: 1-93.

26 Knapp M, Thorgrimsen L, Patel A, Spector A, Hallam, A, Woods B, et al. Cognitive stimulation therapy for people with dementia: cost-effectiveness analysis. Br J Psychiatry 2006; 188: 574-80.

27 Jonsson L, Lindgren $\mathrm{P}$, Wimo A, Jönsson B, Winblad B. Costs of Mini Mental Examination-related cognitive impairment. Pharmaeconomics 1999; 16 409-16.

28 Streater A, Spector A, Aguirre E, Hoe J, Hoare Z, Orrell M, et al. Maintenance Cognitive Stimulation Therapy (CST) in practice: study protocol for a randomized controlled trial. Trials 2012; 13: 91.

29 Clark CM, Sheppard L, Fillenbaum GG, Galasko D, Morris JC, Heyman A. Variability in annual Mini-Mental State Examination score in patients with probable Alzheimer Disease. Arch Neurol 1999; 56: 857-62.

30 Zanetti O, Frisoni GB, De Leo D, Buono MD, Bianchetti A, Trabucci M. Reality orientation therapy in Alzheimer's disease: useful or not? A controlled study. Alzheimers Dis Assoc Disord 1995; 9: 132-8.

31 Metitieri T, Zanetti O, Geroldi C, Frisoni GB, De Leo D, Trabucchi M. Reality orientation therapy to delay outcomes of progression in patients with dementia: a retrospective study. Clin Rehab 2001, 15: 471-8.

32 Woods B, Thorgrimsen L, Spector A, Royan L, Orrell M. Improved quality of life and cognitive stimulation therapy in dementia. Aging Ment Health 2006; 10: 219-26. 
33 Cooper C, Mukadam N, Katona C, Lyketsos CG, Blazer D, Livingston G, et al Systematic review of the effectiveness of pharmacologic interventions to improve quality of life and well-being in people with dementia. Am J Geriatr Psychiatry 2013; 21: 173-80.

34 Cooper C, Mukadam M, Katona C, Lyketsos C, Ames D, Livingston G, et al. Systematic review of the effectiveness of non-pharmacological interventions to improve quality of life of people with dementia. Int Psychogeriatr 2012; 24: 856-70.

35 Selwood A, Thorgrimsen L, Orrell M. Quality of life in dementia-a one-year follow-up study. Int J Geriat Psychiatry 2005; 20: 232-7.

36 Lyketsos CG, Gonzales-Salvador T, Chin J, Baker A, Black B, Rabins P. A follow-up study of change in quality of life among persons with dementia residing in a long-term care facility. Int J Geriat Psychiatry 2003; 18: 275-81.

37 Missotten $\mathrm{P}$, Ylieff M, Di Notte D, Paquay L, De Lepeleire J, Fontaine O. Quality of life in dementia: a 2-year follow-up study. Int J Geriat Psychiatry 2007; 22: 1201-7.

38 Orrell M, Yates L, Burns A, Russell I, Woods RT, Hoare Z, et al. Individual Cognitive Stimulation Therapy for Dementia (iCST Trial). Trials 2012; 13: 172

39 National Institute for Health and Clinical Excellence and the Social Care Institute for Excellence (NICE-SCIE). Dementia: Supporting People with Dementia and their Carers in Health and Social Care. Clinical Guideline 42. NICE and SCIE, 2007.

\section{Wilfred Owen}

Bent double, like old beggars under sacks,

knock-kneed, coughing like hags, we cursed through sludge,

Till on the haunting flares we turned our backs,

And towards our distant rest began to trudge.

Men marched asleep. Many had lost their boots,

But limped on, blood-shod. All went lame, all blind

Drunk with fatigue; deaf even to the hoots

of gas-shells dropping softly behind.

Gas! Gas! Quick boys! - An ecstasy of fumbling, Fitting the clumsy helmets just in time,

But someone still was yelling out and stumbling And floundering like a man in fire or lime. -

Dim through the misty panes and thick green light, As under a green sea, I saw him drowning. In all my dreams, before my helpless sight, He plunges at me, guttering, choking, drowning.

If in some smothering dreams, you too could pace Behind the wagon that we flung him in, And watch the white eyes writhing in his face,

His hanging face, like a devil's sick of sin; If you could hear, at every jolt, the blood come gargling from the froth-corrupted lungs,

Obscene as cancer, bitter as the cud Of vile, incurable sores on innocent tongues, My friend, you would not tell with such high zest To children ardent for some desperate glory, The old Lie: Dulce et decorum est

Pro patria mori.

Selected by Femi Oyebode. 